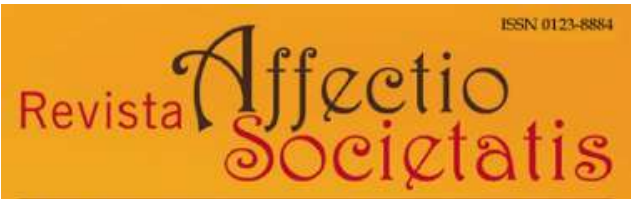

Departamento de Psicoanálisis | Universidad de Antioquia

Revista Affectio Societatis

Departamento de Psicoanálisis

Universidad de Antioquia

revistaaffectiosocietatis@udea.edu.co

ISSN (versión electrónica): 0123-8884

Colombia

2021

Carmen Elisa Escobar

Masoquismo primordial y masoquismo del goce en el surgimiento del sujeto en Lacan

Revista Affectio Societatis, Vol. 18, N. ${ }^{\circ}$ 34, enero-junio de 2021

Art. \# 7 (pp. 1-21)

Departamento de Psicoanálisis, Universidad de Antioquia

Medellín, Colombia 
ARTÍCULO DE REFLEXIÓN

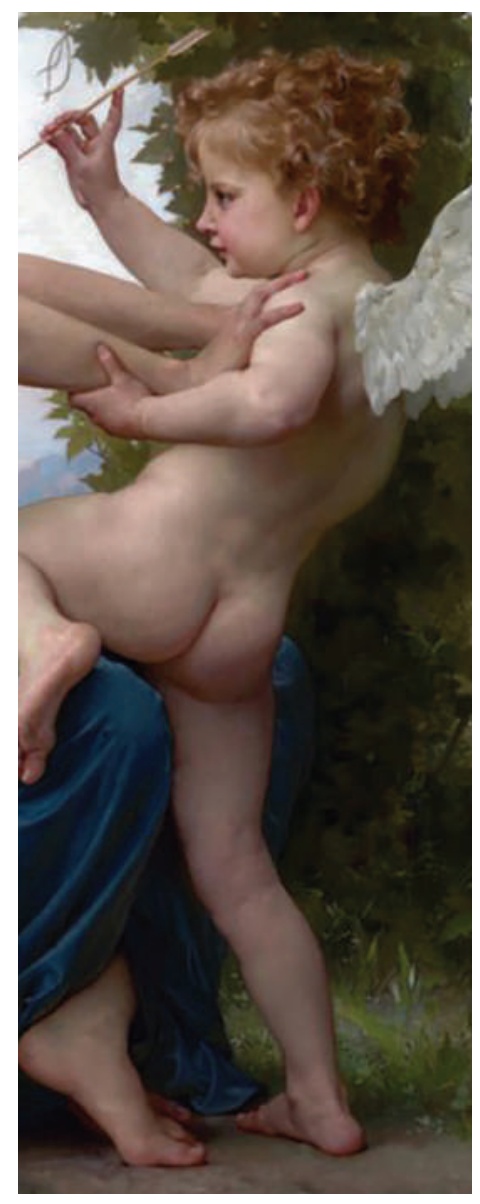




\title{
MASOQUISMO PRIMORDIAL Y MASOQUISMO DEL GOCE EN EL SURGIMIENTO DEL SUJETO EN LACAN
}

\author{
Carmen Elisa Escobar María ${ }^{1}$ \\ Universidad del Norte, Colombia \\ carmene@uninorte.edu.co \\ https://orcid.org/0000-0002-0080-3466
}

DOI: 10.17533/udea.affs.v118n34a07

\section{Resumen}

Para cuestionar la idea freudiana del pasaje de un masoquismo primario a uno secundario, y del masoquismo al sadismo, Lacan prefiere utilizar para el masoquismo llamado primario el calificativo de primordial. De este modo, la idea freudiana de un resto no expulsado de la pulsión de muerte que permanece en el interior del individuo es modificada por Lacan entendiéndola como el dolor a través del cual el sujeto aprehende el dolor de existir al reconocerse como solo un eslabón de la cadena significante. La incorporación del significante, el goce, es fundamentalmente masoquista. Pero es difícil delimitar la diferencia entre el masoquismo inherente a la génesis del sujeto tal como Lacan la presenta, es decir, como resto de la división subjetiva, y su noción de fantasma masoquista en el neurótico o el masoquismo perverso. La noción plus de goce parece moderar esta superposición, como se mostrará en este escrito.

Palabras clave: masoquismo primario, masoquismo primordial, goce, plus de goce, sujeto.

1 Miembro fundador del Círculo Psicoanalítico del Caribe desde 1991. Psicoanalista, psicóloga clínica, especialista en filosofía contemporánea, doctora en filosofía por la UNED (Madrid). Actualmente es profesora de planta del Departamento de Humanidades y Filosofía de la Universidad del Norte. Es investigadora de Studia, Grupo de investigación del Departamento de Humanidades y Filosofía de la Universidad del Norte, en la línea de investigación "Estudios contemporáneos y culturales". 


\section{PRIMORDIAL MASOCHISM AND MASOCHISM OF JOUISSANCE ON THE EMERGENCE OF THE SUBJECT IN LACAN}

\begin{abstract}
Aiming to question the Freudian idea of the passage from primary to secondary masochism, and from masochism to sadism, Lacan prefers to use the qualifier "primordial" for the so-called primary masochism. Hence, Lacan modifies the Freudian idea of a remainder not expelled from the death drive that remains inside the individual, understanding this idea as the pain through which the subject apprehends the pain of existing by recognizing himself merely as a link of the signifying chain - the incorporation of the signifier, the jouissance,
\end{abstract}

is fundamentally masochistic. It is difficult, however, to delimit the difference between his notion of the neurotic's masochistic phantasy or the perverse masochism, and the masochism inherent to the genesis of the subject as presented by Lacan, that is, as a remainder of the subjective division. The notion of surplus jouissance appears to moderate this overlap, as will be shown in this paper.

Keywords: primary masochism, primordial masochism, jouissance, surplus jouissance, subject.

\section{MASOCHISME PRIMORDIAL ET MASOCHISME DE JOUISSANCE DANS L'ÉMERGENCE DU SUJET CHEZ LACAN}

Résumé

Afin de s'interroger sur l'idée freudienne $\mathrm{du}$ passage d'un masochisme primaire à un masochisme secondaire, et du masochisme au sadisme, Lacan préfère utiliser pour le masochisme dit primaire le qualificatif de primordial. Ainsi, l'idée freudienne d'un restant non rejeté de la pulsion de mort qui subsiste chez l'individu est modifiée par Lacan qui l'entend en tant que la douleur par laquelle le sujet appréhende la douleur d'exister en se reconnaissant comme un simple maillon de la chaîne signifiante. L'incorporation du signifiant, la jouissance, est fondamentalement masochiste. Mais il est difficile de délimiter la différence entre le masochisme inhérent à la 
genèse du sujet tel que Lacan le présente, c'est-à-dire comme un reste de la division subjective, et sa notion de fantasme masochiste chez le névrosé ou dans le masochisme pervers. La notion plus-de-jouir semble modérer ce chevauchement, comme nous le montrerons dans cet article.

Mots clés : masochisme primaire, masochisme primordial, jouissance, plus-de-jouir, sujet.

\section{MASOQUISMO PRIMORDIAL E MASOQUISMO DO GOZO NO SURGIMENTO DO SUJEITO EM LACAN}

\section{Resumo}

A fim de questionar a idéia freudiana da passagem de um masoquismo primário para um secundário, e do masoquismo para o sadismo, Lacan prefere usar para o masoquismo chamado de primário o qualificativo de primordial. Desta maneira, a idéia freudiana de um resto não expulsado da pulsão de morte que permanece no interior do indivíduo é modificada por Lacan ao entendê-la como a dor através da qual o sujeito apreende a dor de existir ao reconhecer-se como apenas um elo na cadeia significante; a incorporação do signifi- cante, o gozo, é fundamentalmente masoquista. Mas é difícil delimitar a diferença entre o masoquismo inerente à gênese do sujeito como Lacan a apresenta, quer dizer, como resto da divisão subjetiva, e sua noção de fantasma masoquista no neurótico ou o masoquismo perverso. A noção de mais-de-gozar parece moderar esta sobreposição, como será apresentado neste texto.

Palavras-chave: masoquismo primário, masoquismo primordial, gozo, mais-de-gozar, sujeito.

Recibido: 18/11/2020 • Aprobado: 10/4/2021 
Al efectuar un desplazamiento en la significación de algunas concepciones o nociones freudianas oscuras, y que requerían ser revisadas, Lacan las actualiza, las prolonga, y así estas nociones encuentran un nuevo rendimiento teórico y clínico. Tal es el caso de la hipótesis de un masoquismo primario al que Lacan renombra como masoquismo "primordial". A mi modo de ver, Lacan hace esto, entre otras razones, porque decir primario evoca lógicamente un pasaje a una supuesta posición sádica posterior, lo que no es el caso. Para Lacan no se trata tanto de un primer tiempo de la pulsión, sino un primer tiempo del goce ya incorporado, como expondré más adelante.

Pese a la imposibilidad de pensar en un origen o en un momento originario, el masoquismo como experiencia de un límite más allá del placer es evocado por Freud bajo la figura de testigo o testimonio de la coexistencia originaria de las pulsiones; en Lacan es una consecuencia y resto de la operación de surgimiento de un sujeto. Para Freud (1976/1925, pág. 170), el masoquismo es testigo en la medida en que para explicar la presencia de la agresividad contra sí mismo habría que suponer que queda en el interior del psiquismo un resto no desviado de la pulsión de destrucción, que se vuelve componente de la libido por domeñamiento y que tiene como objeto al ser propio. Para Lacan también el masoquismo es un resto, pero es lo que queda del encuentro con el Otro del significante ${ }^{2}$.

Lacan presta especial atención a lo largo de sus seminarios al ensayo de Freud de 1919, «Pegan a un niño», subtitulado "Contribución al conocimiento de la génesis de las perversiones sexuales", debido a que lo considera un punto de inflexión en el pensamiento freudiano sobre las neurosis y las perversiones y, por supuesto, una contribución ejemplar en la presentación de esa estructura crucial de la subjetividad que es el fantasma (Lacan, 2010/1957-1958, págs. 241-256). Para este escrito interesa especialmente la lectura cruzada que efectúa Lacan entre "Más allá del principio de placer" (Freud, 1979/1920) y

2 En este punto seguiré principalmente, aunque apoyada también en otros seminarios, los planteamientos de Lacan (2008) y los trabajos de Allouch (2009) y Vasallo (2008), quienes se preguntan sobre el carácter masoquista del goce y el masoquismo primordial en la estructuración subjetiva. 
"El problema económico del masoquismo" (Freud, 1976/1925), en la que la pulsión de muerte, lejos de ser rechazada como concepto, será objeto de incesante reconsideración. Es posible seguir un hilo de interpretación: Freud plantea que existiría un "resto" de la pulsión de muerte $^{3}$ que no puede ser tramitado, lo que en su concepción quiere decir que no es expulsado fuera del psiquismo hacia los objetos del mundo exterior y que permanece en el interior. Frente a esto, Lacan (2010/1957-1958) se pregunta si se podría entender ese resto como el dolor ligado a la existencia. ¿Por qué no considerar que el masoquismo sería "aquello a cuyo través el sujeto aprehende el dolor de existir"? (pág. 264).) Que el sujeto se perciba como eslabón de la cadena significante es doloroso, por lo que Lacan propone una especie de dolor constituyente. Esto será alongado hasta decir que el goce es fundamentalmente masoquista.

Algunas puntuaciones respecto del masoquismo perverso son necesarias, como se verá en el cuerpo de este trabajo, pero el objeto en cuestión no es la estructura perversa en sí misma, sino el masoquismo del goce como momento estructural de la operación subjetiva que se encadenará con el deseo. En el seminario "De un Otro al otro", Lacan (2008/1968-1969) efectúa un desplazamiento, que ya venía en gestación, del fetichismo como ejemplarizante en la comprensión de la estructura subjetiva general, al masoquismo. El primero ocupó un lugar central en la demostración (ya que el perverso es un demostrador) de la metonimia del objeto, de la estructura y función del deseo, y del deseo masculino. Lacan considera que Freud extrae su planteamiento sobre el deseo, en general, a partir del deseo perverso, pues este último revela con mayor claridad la estructura de la pulsión llevando al límite el intento de ir más allá del principio del placer: "tan lejos como se puede en el goce" (2008/1960, pág. 785). La más radical de las posiciones perversas respecto al deseo es, en su concepto, el masoquismo, por cuanto es masoquista el goce que se obtiene de la suposición de que el propio destino lo decide el Otro, o que está sometido al juicio del Otro (Lacan, 2008/1968-1969, pág. 783; Lacan, 2014/1958-1959, pág. 506; Izcovich, 2016, pág. 48).

3 Vale subrayar que la pulsión de muerte no podría ser un retorno hacia la nada o a lo inorgánico, como la concebía Freud. 
Hay también un desplazamiento de mira en dos sentidos: a) Desde un punto de vista fenomenológico, cuando afirma que en el masoquismo no se trata tanto de dolor -ya señalado por Krafft-Ebing-como de la función de aproximación o alejamiento de un límite que no está regulado por la experimentación del placer y el displacer; y b) Desde un punto de vista estructural, cuando afirma que en el masoquismo hay una acentuación de la función del objeto a (Lacan, 2014/19581959; Vasallo, 2008). Coincide con Deleuze (2001) en su esclarecedor escrito sobre el masoquismo, Presentación de Sacher-Masoch, en cuanto a que el masoquismo no puede ser definido simplemente como un sadismo vuelto sobre el yo, es decir, que no hay una unidad sadomasoquista, ni complementariedad, ni la supuesta unidad dialéctica que Freud postuló. El uno no es, pues, el reverso del otro. Pero más allá de ese nuevo entendimiento del funcionamiento masoquista perverso en Lacan hay formulaciones en las que es difícil delimitar la diferencia entre la génesis del sujeto en general y el fantasma masoquista que podría habitar a un neurótico.

\section{El masoquismo como problema económico}

En "El problema económico del masoquismo", Freud vuelve a visitar la relación entre el principio del placer -al que había situado como guardián de la vida- y las dos pulsiones con las que concluye en 1920 su prolongada reflexión dualista en torno a la vida pulsional: pulsiones eróticas o de vida y pulsiones de muerte. Es, pues, un nuevo intento de explicar el carácter enigmático de los fenómenos que en sí mismos contradicen el principio placer-displacer. En el caso del masoquismo, el displacer y el dolor, que tendrían que ser advertencias o signos de un peligro que movería a la evitación, por el contrario, parecen constituirse en metas o fines en sí mismos (Freud, 1976/1925, pág. 165).

Como Freud mismo señaló (1976/1905, pág. 144, nota 28), él se vio llevado a postular dicho masoquismo erógeno a partir de los nuevos hallazgos: la estructura del aparato psíquico y la nueva clasificación de las pulsiones (es decir, los desarrollos de "Más allá del principio de placer" y de "El yo y el ello"). Vale decir que ahora el foco de la 
reflexión freudiana (1976/1905, pág. 167) no es el masoquismo como perversión, sino pensar un masoquismo originario a partir de las tres figuras bajo las cuales el fenómeno masoquista se presenta: masoquismo erógeno, femenino y moral. No hay que olvidar, como lo señaló Attié (1994), que además de las pulsiones están en juego el nuevo estatuto del superyó y su relación con las figuras paternas, el padre como agente de la castración y el falo como organizador universal.

Recapitulemos el planteamiento del problema, que es en apariencia sencillo: es evidente que experimentar algo como placentero o displacentero no solo depende de un factor cuantitativo como el aumento o disminución de la tensión Freud (1976/1905, pág. 166), ya que hay tensiones placenteras y distensiones displacenteras, pues es evidente que también intervienen factores cualitativos como el tiempo (ciclos de alternancias, subidas y bajadas de tensión) y el ritmo, los cuales por su misma naturaleza son muy difíciles de definir. Estas observaciones no le impiden reafirmar en las primeras páginas del ensayo, y en aparente contradicción con los dos textos mencionados, que dolor y displacer son solo medios (ni fines, ni señal) para un fin máximo que sería el placer. Como fue señalado por De M’Uzan (1978, págs. 152-153), las nociones de tiempo y cantidad aclaran "la singular complicidad entre dolor y goce", tan evidente como dato clínico, y cómo de la búsqueda infinita de dolor puede deducirse lógicamente la necesidad infinita de placer (De M’Uzan, 1978, pág. 153).

Freud supone en el aparato anímico una tendencia (principio de Nirvana o de constancia) hacia el punto cero de tensión que nombra como pulsión de muerte. Es, pues, por la libido, Eros, que la tendencia del aparato anímico de reducir a la nada, o al mínimo posible la cantidad de excitación, se convirtió en principio del placer ${ }^{4}$. La vida produce la metamorfosis mediante la cual se experimenta como placentero no tener tensión; se trata, pues, de un placer negativo. Los límites entre el placer y el displacer, la vida y la muerte, se desdibujan así en la realidad efectiva que, por su parte, también es un principio. De modo que la vida humana se rige por dos principios, ya que placer-displacer son

4 De allí la clara diferencia entre principio de constancia y principio de placer. 
uno solo, que no se destituyen, sino que coexisten. Pero es una especie de indecidible para Freud; en un momento afirma que:

En general saben conciliarse entre sí, aun cuando en ocasiones desembocará forzosamente en conflictos el hecho de que por un lado se establezca como meta la rebaja cuantitativa de la carga de estímulo, por el otro un carácter cualitativo de ella y, en tercer lugar, una demora en la descarga de estímulo y una admisión provisional de la tensión de displacer. (Freud, 1976/1905, pág. 167).

Sin embargo, aún al final de su vida, Freud considera como un asunto de la mayor importancia teórica saber cuándo y cómo se logra "vencer" al principio de placer:

Y sigue siendo una cuestión de la más alta importancia teórica, que en el presente no se puede responder, averiguar cuándo y cómo se logra en general vencer al principio de placer. La reflexión de que el principio de placer demanda un rebajamiento, quizás en el fondo una extinción, de las tensiones de necesidad (Nirvana), lleva a unas vinculaciones no apreciadas todavía del principio de placer con las dos fuerzas primordiales: Eros y pulsión de muerte. (Freud, 1980/1938, pág. 200. Las cursivas son mías).

Me interesa resaltar que en "Tres ensayos" el problema era expresado de otra manera: la excitación sexual parece un efecto colateral de procesos internos que rebasan cierta intensidad; difícilmente ocurra algo en el organismo, de cierta importancia, "que no ceda sus componentes a la excitación de la pulsión sexual” (Freud, 1976/1905, pág. 169). Toda excitación, entonces, sería susceptible de ser sexual; displacer y dolor se ligan a lo sexual casi de un modo fisiológico (Freud, 1976/1905, págs. 169, 186) $)^{5}$. Cuando Freud distingue dos formas de masoquismo, el llamado "femenino" y el "moral",

5 Solo en este sentido sería admisible la crítica de Laplanche (1996, pág. 191), dirigida a Freud, al considerar que la hipótesis de que lo sexual puede surgir "en los márgenes" de toda actividad somática no solo es biologizante sino también endógena.

6 Todo aquello "que pone a la persona en una situación característica de la feminidad": ser castrado, ser poseído sexualmente o parir (Freud, 1976/1905, pág. 168). No está de más insistir en la posición de Freud (1976/1905, pág. 167) sobre el 
ambas es el "masoquismo erógeno", es decir que sentir placer en el dolor es algo constitucional o biológico. Podemos pensar que es el argumento freudiano para no soslayar el anclaje corporal, último reducto que soporta su teoría de la dinámica pulsional. De este modo, intentando resolver la difícil hipótesis de un dualismo pulsional, considera que existe un masoquismo originario, un resto no desviado de la pulsión de muerte al exterior que permanece en el interior, que se vuelve componente de la libido por "domeñamiento" y que tiene como objeto al ser propio (Freud, 1976/1905, pág. 170). Es, a su modo de ver, masoquismo erógeno, el genuino masoquismo erógeno. Más aún, dicho masoquismo es para Freud el "testigo" de que efectivamente existió una liga entre Eros y pulsión de muerte. Acompañante permanente de la libido, "de la que toma prestados sus cambiantes revestimientos psíquicos" (Freud, 1976/1905, pág. 170), este masoquismo no es el resultado de un sadismo vuelto contra el yo, como habíamos señalado. Numerosos ejemplos clínicos ilustran la sexualización de ese masoquismo primario: angustia de ser devorado por el animal totémico, deseo de ser golpeado por el padre, parir, la castración ${ }^{7}$.

Strachey (Freud, 1976/1905, pág. 143, nota 27) menciona la existencia de dos párrafos en las primeras ediciones de "Tres ensayos" en los que Freud señala "la certeza" de que al menos una de las raíces del masoquismo tenía que ver con la sobreestimación sexual como consecuencia de la elección de objeto sexual. Es decir, la elección de objeto comportaba la sobreestimación del mismo con el consecuente empobrecimiento del yo. De este modo, el masoquismo

masoquismo moral y el femenino tal como los aborda en este texto: por un lado, considera que el masoquismo moral es el más interesante para el psicoanálisis; por otro, que el masoquismo femenino, que no se refiere al masoquismo de una mujer sino al masoquismo en el varón, es resultado de equipar pasividad, femenino y masoquismo. Lacan (2010/1957-1958, pág. 256) radicaliza esa separación desvinculando cualquier pasividad o masoquismo de la feminidad, lo que lleva a plantear que el masoquismo femenino es un fantasma masculino.

7 Laplanche (1996, pág. 195) pone en duda la validez de la afirmación freudiana de que la fantasía de parir tenga un carácter y una función masoquista. Su duda tiene que ver con la "falsedad" de Freud cuando justifica solo hablar de masoquismo femenino en los hombres en razón de la escasez de material, siendo que en "Pegan a un niño", su análisis está basado en el relato de la fantasía de cuatro mujeres. 
era entendido como el efecto sobre el yo de la irrupción del amor por el otro, amor que implica una posición que podría ir desde la pasividad frente al objeto hasta la pasividad frente a la vida en su totalidad, estando en el extremo la satisfacción en el sufrimiento y el dolor (Freud, 1976/1905, pág. 144).

El enigma, no obstante, persiste: ¿cómo explicar ese masoquismo?, ¿cómo explicar que el dolor y el displacer puedan ser metas ellos mismos? Y más si pensamos en un masoquismo que no tiene que ver con una vuelta del sadismo sobre sí mismo, ya que, como se ha señalado, parece estar activo en los tiempos originarios. Y tampoco resuelve el problema considerarlo como perversión que, por otra parte, no es el objeto de interés principal para Freud, porque cuando lo plantea como pareja del sadismo señala que ese par antitético tiene una posición especial que lo hace "sobresalir" en el conjunto de las perversiones (Freud, 1976/1915), y lo justifica por su origen pulsional, que no podría entenderse más que como conjunción de las pulsiones de vida y muerte (Freud, 1976/1905, pág. 145, nota 31).

En la parte final del ensayo de 1924, el masoquismo primario (erógeno) y el moral vienen a ser lo mismo en la medida en que el masoquismo moral "pasa a ser el testimonio clásico de la existencia de las pulsiones" (Freud, S. (1976/1925 pág. 176), específicamente es lo que no pudo ser exteriorizado como pulsión de destrucción ${ }^{8}$ pero que tiene el valor psíquico de un componente erótico y por esto la contundente afirmación de Freud (1976/1920, pág. 176) de que "ni aún la autodestrucción de la persona puede producirse sin satisfacción libidinosa".

Para Lacan se trata de otro problema: de la subordinación del placer a la ley del significante. Por ello equiparará pulsión de muerte y masoquismo primordial del goce diciendo que se trata de metáforas, relámpagos, reflejos de un mismo misterio "y que se llama sexualidad" (Lacan, 1965-1966).

8 Dice Freud (1976/1925, pág. 169) que esa desviación hacia el exterior "recibe entonces el nombre de pulsión de destrucción, pulsión de apoderamiento, voluntad de poder". 


\section{Masoquismo y sujeto}

«Pegan a un niño», el ensayo de 1919 ya mencionado, contribuye a descartar toda consideración de las perversiones como modos de satisfacción directa de la pulsión o de puesta al desnudo de la misma. Lacan (2010/1957-1958, pág. 241) lo confirma: hay tanta sutileza, complejidad, parcialidad, juego significante en el "tratamiento" de la pulsión en las perversiones como en las neurosis. Por otra parte, Lacan trabaja, en varias lecciones de sus seminarios ${ }^{9}$, la dialéctica de los tres tiempos de la fantasía estudiada por Freud que acompaña la excitación sexual y posterior masturbación de algunos casos en análisis ${ }^{10}$. A partir de una fase terminal de dicha fantasía, tal como es recordada por el sujeto ("pegan a un niño", alguien pega a un niño, así de modo indeterminado ${ }^{11}$ ), Freud reconstruye una primera fase que el sujeto puede recordar y en la cual la figura que da la paliza es identificada como una figura de autoridad masculina, es decir en la vertiente de la constelación paterna (el padre pega a un niño que no es el sujeto). Una segunda fase, plenamente olvidada, esto es caída bajo represión, será una construcción en el análisis: el niño que recibe la paliza es el propio sujeto.

Lo que me interesa resaltar de la lectura lacaniana es el hecho de otorgar a dicha fantasía el carácter de solución fantasmática al problema de la existencia, pues este agente de la paliza (en este caso el Otro, padre) amenaza al sujeto con su abolición: ya se trate del niño a quien le pega en la primera fase, en la medida en que no es amado, ya sea el propio sujeto, golpeado en la fase reprimida, ambas apuntan a la mortificación en el encuentro con el Otro del significante, en la que cualquier signo podría ser tomado como amenaza, como rechazo.

El látigo [que para Lacan será un signo de la relación con el deseo del Otro] tiene en sí mismo el carácter, tiene la naturaleza de algo

9 Me refiero concretamente a las lecciones del 5 y 12 de febrero de 1958 del seminario Las formaciones del inconsciente (Lacan, 2010/1957-1958).

10 Hay que recordar que Freud presenta en el texto seis casos, cuatro mujeres y dos hombres (ver nota 6).

11 Incluso a varios niños. 
que en el plano simbólico (las cursivas son mías), y subrayo que en un primer momento se trata de la entrada de lo Simbólico en el cuerpo, se expresa como una tachadura, pues lo que interviene ante todo es algo que borra al sujeto, lo tacha, lo anula, algo significante. (Lacan, 2010, pág. 250, énfasis añadido).

Lo que pone en escena la fantasía de flagelación es pues la relación entre el significante y el cuerpo. El Otro, el significante, marca el cuerpo como carne que goza y de la que se puede gozar. Es lo que Lacan llama la "gloria de la marca" en el Reverso del psicoanálisis ${ }^{12}$ y que ubica en la raíz del fantasma. Deja pensar que la marca hace al cuerpo glorioso porque mereció del Otro que dejará su marca en él como signo de que acusa recibo de su existencia (la del sujeto flagelado). Como señala Miller (2015, pág. 251), la marca también es un significante paradojal: "no entra en un sistema que sería la estructura de lenguaje; vale como una insignia, solitaria, absoluta, que identifica un cuerpo como objeto de goce".

Para entrar de otra manera al tema quisiera extraer dos afirmaciones que forman parte de la elaboración lacaniana respecto al deseo y el goce, expresadas de múltiples maneras a lo largo de su enseñanza, con acentos desplazados y sin que puedan considerarse cerradas: la primera, y que está en la base de la doctrina lacaniana, es la que sostiene que el deseo se constituye a partir del deseo del Otro, y específicamente que el sujeto recibe su marca mayor, la del trazo unario ${ }^{13}$, de un punto de carencia del Otro (Lacan, 1961-1962). De este modo se abre,

12 Lección del 14 de enero de 1970.

13 Lacan tradujo al francés el término alemán "einziger" como "unaire". Con este adjetivo introduce la noción de "trazo único" (einziger Zug) de Freud explicada en "Psicología de las masas y análisis del yo", para presentar la marca de ingreso en el lenguaje. La entrada en el Diccionario del psicoanálisis dirigido por Roland Chemama (1998) dice: “El rasgo unario es el significante en tanto es una unidad y en tanto su inscripción hace efectiva una huella, una marca. En cuanto a su función, está indicada por el sufijo «-ario», que evoca, por una parte, el conteo (este sufijo se emplea para formar sustantivos de valor numeral) y, por otra parte, la diferencia (los lingüistas hablan de 'rasgos distintivos binarios', 'terciarios')". Lacan dice que lo toma de la teoría de conjuntos (lección del 13 de diciembre de 1961). En francés, trait significa tanto trazo (como el del lápiz) y rasgo (como 
entonces, constantemente, la pregunta por la relación del sujeto con el objeto de su deseo. El objeto es definido como el soporte que el sujeto se da, puesto que desfallece, en ese discurso del Otro que es el inconsciente: algo falta en el sujeto por la estructura misma que instaura la relación del sujeto al Otro, como de la palabra, algo falta al nivel del Otro, pero es lo que permite al sujeto identificarse allí y ese mismo algo hace que el sujeto, al mismo tiempo, desaparezca allí como tal. El deseo humano tiene esa propiedad de estar fijado o asociado no a un objeto sino a un fantasma, estructura que "garantiza al soporte del deseo su estructura mínima" (Lacan, 2014/1958-1959, pág. 405). El sujeto intenta capturarse en su desaparición, puesto que esto es el fantasma: "enfrentamiento perpetuo entre la $S$ tachada y la a minúscula", lo que equivale a decir que el fantasma es un intento de estar representado en el momento de su desaparición (Lacan, 2014/19581959, pág. 462), pero "no encuentra nada en el Otro que lo garantice de una manera segura y cierta, que lo autentifique, que le permita situarse y nombrarse en el discurso del Otro, es decir, en calidad de sujeto del inconsciente" (pág. 418).

Más aún, el objeto $a$, resto de la operación subjetiva, revela la separación entre el deseo y el goce en la sexualidad, pues estamos condenados a que el goce no esté destinado al deseo y que el deseo entonces no haga más que ir a su encuentro, para lo cual debe no solo comprender sino franquear el fantasma que lo construye y sostiene (Lacan, 2012, pág. 358). Dicho de otra manera, la pequeña fórmula condensa lo que mantiene a un sujeto como deseante, lo que quiere decir también estar sostenido por un más allá del discurso (Lacan, 2014/1958-1959, pág. 504). En cuanto al perverso, trata de "apuntar al deseo del Otro (al corazón del Otro), y creer ver allí un objeto" (págs. 467, 518). Cree ver el objeto, porque en realidad el objeto $a$ nunca se ajusta al deseo (pág. 418) ${ }^{14}$.

los de la cara). En 1972, utilizó "uniano" para referirse a otro tipo de unidad: la especular imaginaria.

14 El falo sigue auxiliando al psicoanálisis para representar el carácter evanescente del objeto del deseo, pero también al deseo mismo, ese significante del deseo, de lo que abrocha el sentido, y que Lacan ubica como privilegiado, para señalar, por último, que el falo es la falla en la significación, pues toda significación es 
En el seminario sobre la angustia en 1962, en el que describe paso a paso la división subjetiva, Lacan pone el goce al comienzo como si el sujeto antes de constituirse en tal fuese una determinada cantidad de goce, pero situada en el Otro (Allouch, 2009, pág. 217), de lo cual, luego del advenimiento subjetivo operado por el lenguaje con la consecuente pérdida de goce, surgirá el sujeto deseante. Dicha pérdida de goce, entonces, posibilitaría el acceso al deseo.

\section{Carácter masoquista del goce y repetición}

Como consecuencia de la afirmación ya enunciada, es decir, que el deseo se constituye a partir del deseo del Otro, surge una segunda hipótesis: la pérdida de goce, la castración, es el precio que se paga para localizarse a sí mismo en algún lugar. Los ritos de iniciación de las sociedades primitivas, incluida la mutilación, por ejemplo, dan cuenta de que se busca darle a los deseos (naturales) una función en la que pueda localizarse el ser del sujeto, identificarse allí (Lacan, 2014/1958-1959, pág. 430).

Esta noción de pérdida en Lacan está muy conectada con la idea del excedente sexual de Freud, excedente que impide la traducción a la lengua del síntoma, como lo había expresado en los comienzos del psicoanálisis a Fliess (Freud, 2008/1925, pág. 198); pero también a la definición lacaniana de sujeto: si un sujeto es lo que puede ser representado por un significante para otro significante, esa pérdida de identidad, en el sentido que ya no es más idéntico a sí mismo, implica una pérdida de goce (Lacan, 2008/1968-1969, pág. 20). La función del plus de goce que propone Lacan en el seminario De un Otro al otro, en

incapaz de recubrir lo que corresponde al sexo: "La esencia de la castración, es lo que en esta otra relación de ocultación y de eclipse, se manifiesta en esto: que la diferencia sexual no se soporta más que de la Bedeutung (significación) de algo que falta, bajo el aspecto del falo" (Lacan, 1966-1967). Dado que el deseo se inscribe a partir de una contingencia corporal (Lacan, 1995/1972-1973, pág. 113) y el falo es el significante del deseo, es un significante privilegiado en la medida que permite articular la relación entre sexualidad y lenguaje. 
la lección del 13 de noviembre de 1968, es una especie de renuncia al goce bajo el efecto del discurso que da su lugar al objeto $a$, y este último es presentado como equivalente del plus de goce. Ese "más" es la parte de lo sexual que no puede pasar al lenguaje, pero que no cesa de buscar ser absorbida, subsumida. Lo que se gana por el uso de la palabra se pierde en goce porque hay ordenamiento, limitación, etc., y el sujeto busca recuperarlo para compensar el goce perdido (Izcovich, 2016, pág. 32). Tanto la búsqueda de compensación como el empuje a los objetos son relativos al advenimiento subjetivo.

Hay, pues, un masoquismo primordial del goce inherente a todo sujeto, ya planteado desde el seminario El objeto del psicoanálisis, en la lección del 8 de junio de 1966. El hecho de que en 1953 Lacan haya tildado de caduca la noción de masoquismo primordial se entiende en la medida en que lo simbólico en ese momento representaba la asunción del sujeto de su historia y la repetición simbólica era la posibilidad de ese dominio: "Entonces ya no es necesario recurrir a la noción caduca del masoquismo primordial para comprender la razón de los juegos repetitivos en que la subjetividad fomenta juntamente el dominio de su abandono y el nacimiento del símbolo" (Lacan, 19661967). La introducción del significante, unos años después, es otro modo de entender la intrusión de lo simbólico en lo real, y viceversa.

El problema que surge es cómo explicar que con la noción de plus de goce se indique una pérdida y al mismo tiempo una "bonificación" (Allouch, 2009, pág. 217). Ahora bien, si todo goce está orientado hacia su propio fracaso, por cuanto el goce es la razón de ser de la repetición, cómo no pensar que es un goce masoquista. De allí la ejemplaridad, según Lacan, de la posición masoquista como una manera de obrar con la pérdida de goce constituida por el agravamiento de la separación entre cuerpo y goce que se produce en la escena traumática en la que se encarna la función del Otro. Lacan plantea, en la sesión en la que compara el lugar del pensamiento en Hegel y Freud ${ }^{15}$, que la función del Otro se encarna en el cuerpo que se percibe como separado del goce: el Otro es quien goza. En el nivel del plus de goce,

15 Lección del 23 de abril de 1969. 
el sujeto asume la posición de pérdida, asume la posición de desecho representada en el objeto $a$ (Allouch, 2009, pág. 219) ${ }^{16}$.

Lacan reitera el carácter masoquista del goce en la clase del 14 de enero de 1970. Su punto de partida sigue siendo el mismo, es decir, el segundo paso efectuado por Freud para entender la agresividad y destructividad humanas planteando la existencia de una pulsión de muerte. Es en la medida que hay búsqueda del goce como repetición que se puede pensar la repetición como lo que va contra la vida. El rasgo unario es lo que rige lo esencial del efecto de la repetición. Esta se encuentra ligada a lo que Freud designa como el objeto perdido, tan enfatizado por Lacan: "el goce se busca en un esfuerzo de reencuentro, y que solo se lo podría reencontrar cuando se lo reconoce por el efecto de la marca. La marca misma introduce en el goce la huella con hierro candente de la que resulta la pérdida" (Lacan, 2008, pág. 111).

Ahora bien, el carácter masoquista del goce no se debe solamente al fracaso inherente a la repetición, ni al hecho de que el goce conduce al organismo a su propia muerte, sino a esa primera inscripción del rasgo unario en el cuerpo (Allouch, 2009, pág. 220). La marca es en sí misma conductora de voluptuosidad, dice Lacan, a tal punto que encuentra en la marca en la piel producida por la flagelación la equivalencia que establece entre "el gesto que marca y el cuerpo, objeto de goce" (Lacan, 1992/1969-1970, pág. 52). Por esto habla de la "gloria de la marca", ya mencionada.

Lacan define el significante como aparato del goce y la noción de pérdida vuelve a ser planteada en términos de entropía: la imposición del rasgo unario está en relación con un saber que produce entropía. Todo lo que se puede esperar del sujeto son prácticas de recuperación, recuperar la pérdida de goce. Es la pérdida la que introduce la

16 Vale agregar que la perversión es pensada en dicho seminario, en la clase del 13 de noviembre de 1968, de manera un poco distinta a seminarios anteriores: no pasa por la norma sexual, y en ese sentido continúa la hipótesis freudiana de que la perversión siempre lo es respecto a la norma sexual. Pero es el masoquismo el que está ahora en el centro de la reflexión; y ocurre cuando, curiosamente, el fetichismo de la mercancía también ocupa un lugar clave en el seminario. 
repetición (Lacan, 1992, pág. 51). El plus de goce no es el goce mismo, sino lo que responde a su pérdida, y esta será la causa conjugada del deseo de saber y de la animación "feroz" que nos encadena a ese plus (Lacan, 2006/1975-1976, págs. 104-105). Lacan plantea que para Freud en el fondo el goce es masoquista, aunque se trate de una metáfora. No obstante, Allouch (2009, pág. 220) ve en el plus de goce una especie de moderación de la afirmación radical sobre el masoquismo del goce, en razón de que ese plus, ese un poco más, se obtiene solo mediante una renuncia ${ }^{17}$.

\section{Goce de lo real}

Vasallo (2008, págs. 9-32) subraya que en Lacan el masoquismo primordial converge con la elaboración estructural del sujeto y el Otro. De hecho, en la sesión del 6 de marzo de 1963 del seminario La angustia, Lacan relaciona la fórmula de la división del sujeto en el Otro, de la que el sujeto surge como resto, y la elaboración de la perversión (Lacan, 2006/1962-1963, págs. 171-183). Años atrás, en el seminario La identificación, en la sesión del 13 de junio de 1962, intentando explicar que, paradójicamente, el punto de carencia del Otro es de donde el sujeto recibe su marca mayor, es decir la del rasgo unario, Lacan dice que "el neurótico como el perverso, como el psicótico mismo, no son sino caras de la estructura normal". Los asistentes a su seminario le dicen, ipero háblenos del deseo normal! Y él responde que de eso habla todo el tiempo: "El neurótico, es el normal en tanto que para él el Otro (...) tiene toda la importancia. El perverso, es el normal en tanto que para él el Falo -con mayúscula- tiene toda la importancia. Para el psicótico el cuerpo propio tiene toda la importancia" (Lacan, 19611962, 13 de junio de 1962, s.p.). No son aquí más que caras...

De tal modo que para Lacan la relación de todo sujeto con el goce es intrínsecamente masoquista, lo que plantea de modo acuciante en

17 Para Lacan (2008/1968-1969, pág. 252), el principio del placer es la barrera al goce que está metaforizada por la prohibición de la madre para limitar el goce. La castración es así un "agujero en la aprehensión" del goce del Otro. 
De un Otro al otro. No obstante, habría que hacer una distinción entre el masoquismo como resto de la operación de advenimiento subjetivo y el síntoma masoquista, que es igual a diferenciar entre la génesis del sujeto como resto del Otro y el fantasma masoquista propiamente dicho ${ }^{18}$, en donde el sujeto quisiera encarnar ese resto como una "nada" o un "desecho" (Vasallo, 2008, pág. 14). Ese resto es el que cumplirá en dicho seminario la función de plus de goce. Es que para Lacan el goce masoquista, que es la forma más característica de la función causa de deseo, es un goce analógico: "El sujeto asume de manera analógica la posición de pérdida, de desecho, representada por el $a$ en el nivel del plus de gozar" (Lacan, 2008, pág. 123). En este último caso, en el fantasma masoquista, se trata de la acentuación de la operación de división subjetiva. El masoquista instaura de antemano una regulación, un contrato, para desplegar en una escena su lugar de desecho, en una escenificación (por ejemplo, ubicarse como perro debajo de una mesa, ser humillado, rebajado, etc.) claramente acordada con el Otro.

Lo que cuenta en el masoquismo es la función de aproximación o alejamiento de un límite que no está dado por la experiencia del placer y el displacer, y aunque ese límite solo nos lo podemos representar por la finalización de la vida biológica, desembocar en la muerte no es lo que caracteriza al masoquismo, sino la aproximación a un punto límite en lo simbólico. El masoquismo no tiene tanto que ver con una complacencia en el sufrimiento, sino "con una lógica por la cual el plus de goce se acerca o se aleja de un límite sin totalizar nunca lo Otro como Uno" (Vasallo, 2008, pág. 22). Quiere decir que representa la pérdida que es imposible de contar o medir y a la que Lacan le pone una letra: $a$, objeto $a$. Para Vasallo (2008, pág. 245), Lacan señala una analogía entre el goce masoquista y el plus de gozar solo en virtud de que atribuye al objeto $a$ la función de no poder medir el goce basado en un saber de objeto, imposibilidad a la que el masoquista responde acentuando la posición de objeto que el sujeto mismo ocupa. Asu-

18 En El objeto del psicoanálisis, Lacan (1966) plantea una distinción respecto a la respuesta perversa del sujeto: "La respuesta perversa lleva siempre en ella una negación del otro en tanto sujeto, la identificación perversa se hace siempre en función de un objeto fuente de goce para un falo tan potente como fantasmático" (s.p.). 
miría, pues, esa pérdida ya sea en un discurso sublimatorio, ya sea encarnando inconscientemente el desecho.

Lacan plantea en el seminario Les non-dupes errent, en la sesión del 19 de febrero de 1974, que el masoquismo se inventa, lo que podría entenderse como un discurso sobre la imposibilidad de determinar el límite entre el placer y el goce, y la imposibilidad de medir la pérdida, ya mencionada. Allí dice que todos nos inventamos un truco para colmar el agujero real en lo simbólico, la represión misma: “El masoquismo se inventa y que no está al alcance de todo el mundo, que es una manera de establecer una relación allí donde no hay la menor relación, entre el goce y la muerte" (Lacan, 2013, s.p.).

No deja de resultar interesante subrayar el comentario de Lacan en la Lógica del fantasma (16 de mayo de 1967, pág. 294) respecto al texto de Edmund Bergler, La neurosis básica, en el que interroga el masoquismo en los sujetos que buscan secretamente ser rechazados, a los que nombra como "coleccionistas de injusticias". Todo esto bajo la suposición, dirá Lacan, de que "ser admitidos" por el Otro sería lo mejor que le puede pasar a alguien. Lacan invierte esta proposición de Bergler para considerar que no se trata de la compulsión masoquista a la insatisfacción, sino un desvío, un escape de la devoración, de la asimilación o del riesgo de intrusión. Entonces "hacerse rechazar" podría ser salvarse a sí mismo de ser engullido por el Otro, del sistema que pretende persuadirnos del error de no aceptar su alimento.

Cuando en el seminario El objeto del psicoanálisis, en la clase del 8 de junio de 1966, habla de "masoquismo primordial del goce", lo vincula a la verdad de la pulsión de muerte, por cuanto la muerte no se manifiesta sino en lo perdido de la repetición de la marca inaugural. Y si menciona un sujeto "al goce" después de haber utilizado un sujeto "del significante" es para oponerse, según Vasallo (2008, pág. 17), a "lo que siempre consideró como la ilusión filosófica de reabsorber especulativamente el sujeto en un Uno sin resto -pretensión focalizada sobre todo en Hegel, pero ampliamente desarrollada con referencia a Parménides". Llega a oponer así el sujeto del goce al sujeto de la filosofía a partir de su relectura del masoquismo primordial. 
Destacar la yuxtaposición ambigua del masoquismo perverso y de la función del plus de goce significa rescatar en todo su valor el estatuto de resto del sujeto, lo que desembocará en la búsqueda de aquello en lo que se "soporta" un sujeto, encontrando una casi última denominación del humano afectado de inconsciente: somos parlêtre, conjugación de palabra y goce.

Para concluir, resulta indispensable introducir la afirmación de Lacan, en 1976, de que gozar de lo real implica al masoquismo (Lacan, 2006/1962-1963, pág. 76). En su ternario R, S, I, el goce es, está, viene, de lo real. Más aún, el máximo de goce que puede producir lo real al humano es el masoquismo. Para acentuar esta afirmación vuelve a la distinción entre lo verdadero y lo real. Según Lacan, Freud apunta a esa distinción: lo verdadero produce placer, lo real no necesariamente: "El masoquismo, que es lo mayor del goce que da lo real, él lo descubrió, no lo había previsto inmediatamente." (Lacan, 2006/19621963, pág. 76, énfasis añadido). Esto conlleva la pregunta por la línea delgada que separa a todo "hablaser" de la locura.

\section{Referencias}

Allouch, J. (2009). El sexo del amo. El erotismo desde Lacan. Cuenco de Plata. Attié, J. (1994). Le masochisme, un concept freudien. Quarto, Revue de Psychanalyse, (55), 3-5.

Chemama, R. (Ed.). (1998). Diccionario de psicoanálisis. Amorrortu Editores.

Deleuze, G. (2001). Presentación de Sacher-Masoch. Lo frío y lo cruel. Amorrortu Editores.

De M’Uzan, M. (1978). Del arte a la muerte: un itinerario psicoanalítico. Icaria.

Freud, S. (1976/1905). Tres ensayos de teoría sexual. En J. Strachey (Ed.) y J.L. Etcheverry y L. Wolfson (Trads.). Obras completas (vol. VII, págs. 111222). Amorrortu Editores.

Freud, S. (1976/1915). Pulsiones y destinos de pulsión. En J. Strachey (Ed.) y J.L. Etcheverry y L. Wolfson (Trads.). Obras completas (vol. XIV, págs. 105-134). Amorrortu Editores.

Freud, S. (1976/1925) El problema económico del masoquismo. En J. Strachey (Ed.) y J.L. Etcheverry y L. Wolfson (Trads.). Obras completas (vol. XIX, págs. 161-176). Amorrortu Editores. 
Freud, S. (1979/1919). «Pegan a un niño». Contribución al conocimiento de la génesis de las perversiones sexuales. En J. Strachey (Ed.) y J.L. Etcheverry y L. Wolfson (Trads.). Obras completas (vol. XVII, págs. 177-200). Amorrortu Editores.

Freud, S. (1979/1920). Más allá del principio de placer. En J. Strachey (Ed.) y J.L. Etcheverry y L. Wolfson (Trads.). Obras completas (vol. XVIII, págs. 1-62). Amorrortu Editores.

Freud, S. (1980/1938). Esquema del psicoanálisis. En J. Strachey (Ed.) y J.L. Etcheverry y L. Wolfson (Trads.). Obras completas (vol. XXIII, págs. 133-209). Amorrortu Editores.

Freud, S. (2008/1925). Cartas a Wilhelm Fliess: 1887-1904 (J.L. Etcheverry, trad.). Amorrortu Editores.

Izcovich, L. (2016). La perversión y el psicoanálisis. Universidad Pontificia Bolivariana.

Lacan, J. (1961-1962). La identificación. Versión para circulación interna de la Escuela Freudiana de Buenos Aires (R. R. Ponte, trad.). Inédito.

Lacan, J. (1965-1966). El objeto del psicoanálisis. Versión comparada de Jorge Tarella para la Escuela Freudiana de la Argentina. Inédito.

Lacan, J. (1966-1967). La lógica del fantasma (P. Sanmiguel, trad.). Inédito.

Lacan, J. (1992/1969-1970). El seminario, Libro 17: El reverso del psicoanálisis (1 $1^{\mathrm{a}}$. ed.). (E. Berenguer y M. Bassols, Trads.). Paidós.

Lacan, J. (1995/1972-1973). El seminario, Libro 20: Aún (D. Ravinovitch, Delmont-Mauri y J. Sucre, Trads.). Paidós.

Lacan, J. (2008/1960) "Subversión del sujeto y dialéctica del deseo en el inconsciente freudiano". En Escritos, Siglo XXI Editores (págs.773-807).

Lacan, J. (2012/1962-1963). El seminario, Libro 10: La angustia (E. Berenguer, trad.). Paidós.

Lacan, J. (2006/1975-1976). El sinthome (N. González, Trad.). Paidós.

Lacan, J. (2008/1968-1969). El seminario, Libro 16: De un Otro al otro. Paidós

Lacan, J. (2010/1957-1958). El seminario, Libro 5: Las formaciones del inconsciente (E. Berenguer, trad.). Paidós.

Lacan, J. (2013). Les non-dupes errent (R. R. Ponte, trad. español). Inédito. http://www.valas.fr/IMG/pdf/S21_NON-DUPES---.pdf

Lacan, J. (2014/1958-1959). El seminario, Libro 6: El deseo y su interpretación (G. Arenas, trad.) Paidós.

Laplanche, J. (1996). Masoquismo y teoría de la seducción generalizada. En S. Bleichmar (trad.). La prioridad del otro en psicoanálisis (págs. 189-206). Amorrortu Editores.

Miller, J-A. (2015). Sutilezas analíticas. Paidós.

Vasallo, S. (2008). Escribir el masoquismo. Paidós. 